\title{
Pengumpulan Data Biotik Dalam Studi Lingkungan Kuna
}

nfn. Siswanto

Keywords: natural history, biology, environmental archaeology, method

\section{How to Cite:}

Siswanto, nfn. Pengumpulan Data Biotik Dalam Studi Lingkungan Kuna. Berkala Arkeologi, 15(2), 62-70. https:/ / doi.org/10.30883/iba.v15i2.661

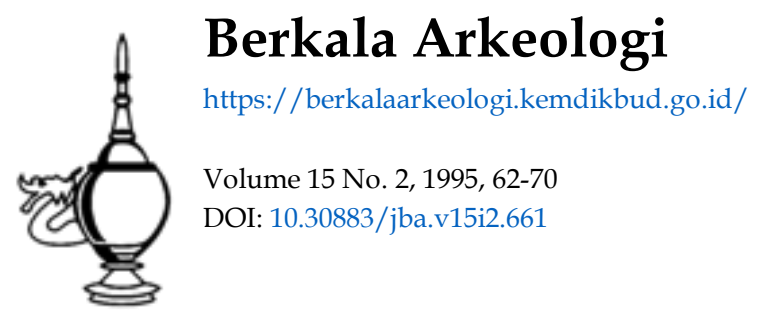

\section{(c) (1) (2)(2)}

This work is licensed under a Creative Commons Attribution-NonCommercial-ShareAlike 4.0 International License. 


\title{
PENGUMPULAN DATA BIOTIK \\ DALAM STUDI LINGKUNGAN KUNA
}

\author{
Siswanto \\ (Balal Arkeologi Yogyakarta)
}

\section{Pendahuluan}

Keseimbangan alam dalam etika lingkungan berarti keseimbangan antara ekosentrisme dan antroposentrisme (kepentingan manusia). Alam dapat dikatakan seimbang bila dapat mendukung kebutuhan manusia tetapi tidak mengakibatkan mundurnya kualitas dan daya dukung alam itu sendiri, sedangkan upaya yang diperlukan untuk mencapai keseimbangan alam adalah dengan usaha mempertahankan kemampuan ekosistem melalui konservasi ekosistem. Data arkeologi (artefak, ekofak dan feature) berperan penting dalam konservasi ekosistem tersebut, karena untuk dipelajari masa sekarang dan masa yang akan datang perlu mempelajari apa yang telah terjadi di masa lampau (what happened before) (Martopo, 1994). Ini bukan berarti bahwa kita kembali ke peradaban manusia masa lampau dan terpaku pada sistem umum, melainkan kita memerlukan suatu fokus pada komponen ekosistem termasuk tingkah laku manusia, untuk memonitor suatu komponen pada periode yang panjang dan untuk mempelajari interaksi mereka.

Sejarah alam lingkungan ini dapat dipelajari melalui sumber daya lingkungan (fisik dan biotik) bersama dengan sumber daya arkeologi Dengan demikian, peranan studi arkeologi sebagai penunjang dalam studi lingkungan sudah jelas sehingga hal ini bisa sebaliknya, untuk kepentingan studi arkeologi diperlukan pendukungnya dengan melaksanakan studi lingkungan masa lampau.

Sehubungan dengan itu, pendekatan interdisipliner menjadi sangat penting untuk membuat suatu kesepakatan penting mengenai data sejarah alam, pendekatan-pendekatan tersebut untuk membuat suatu ekspedisi yang melibatkan banyak pihak sebagai suatu bagian dalam penelitian arkeologi (Watson dkk., 1971). Lebih lanjut, Watson dkk. mengungkapkan bahwa hal penting dari usaha tersebut misalnya mengumpulkan data flora dan fauna prasejarah, iklim, dan distribusi situs-situs arkeologi.

Data arkeologi adalah segalanya dalam proses studi arkeologi, apapun bentuk dan berapa-pun jumlahnya. Data tersebut sebagai fakta histori yang ingin kita serap informasinya, melalui segala atribut yang melekat padanya untuk mengungkap budaya manusia masa lampau 
yang dapat menunjukkan gambaran lingkungan waktu itu

Keterbatasan data arkeologi sering menjadi kendala, karena penerapan metode pengumpulan data belum maksimal. Demikian pula, dalam studi lingkungan kuna, keterbatasan data merupakan kendala, maka upaya yang harus dilakukan adalah mendapatkan data itu dengan menggunakan teknik dan metoda pengumpulannya.

Selain memerlukan data pokok unsur lingkungan, studi lingkung. an kuna juga memerlukan data pendukung yang terkait sebagai komponen lingkungan lainnya. Karena pengertian lingkungan menyangkut unsur sumberdaya lingkungan, maka sumberdaya lingkungan tersebut terdiri atas sumberdaya fisik (tanah, mineral, tambang, air), sumberdaya biotik (flora, fauna dan mikroba), dan sumberdaya fosil hasil perubahan ekologi biota masa lampau (Martopo, 1994).

Sebagai langkah awal, studi lingkungan kuna yang dilaksanakan oleh Balai Arkeologi Yogyakarta adalah studi lingkungan candi, dengan membatasi studi lingkungan mikro, yaitu hanya telaah adanya indikator permukiman dan lingkungan biotisnya. Berdasarkan hal itu maka dalam studi tersebut digunakan metoda dan teknik pengumpulan data disesuaikan dengan tujuannya. Mengingat variabel lingkungan sangat luas maka dalam bahasan ini dibatasi pada pengumpulan data biotis, meskipun terdapat kemungkinan penggunaan data fisis dalam perkembangan studi lingkungan kuna.

Metoda pengumpulan data lingkungan biotik dapat dilakukan melalui temuan permukaan tanah, ekskavasi maupun pengeboran, hal ini disesuaikan dengan penggunaan tekniknya. Sebagaimana diketahui data biotik meliputi sisa-sisa binatang dan tumbuhan. Sisa binatang berupa tulang, gigi, maupun tanduk sering didapatkan lebih menonjol daripada sisa tumbuhan dalam ekskavasi. Karena tulang dengan kandungan unsur kapurnya lebih bertahan terhadap dekomposisi daripada tumbuhan. Namun secara umum dari segi jumlah ternyata sisa tumbuhan lebik banyak, tetapi sisa tersebut kebanyakan dalam bentuk kecil (mikroskopis), misalnya serbuk sari (pollen).

\section{Permasalahan}

Permasalahan dalam studi lingkungan kuna terutama pada keterbatasan data. Data yang diperlukan adalah data arkeologi (artefak) dan data komponen lingkungan. Metoda dan teknik perolehan data tersebut telah banyak dilaksanakan oleh para ahli, namun untuk perkembangan penelitian arkeologi lingkungan di Indonesia belum banyak dilaksanakan. Mengingat manfaat studi lingkungan kuna terhadap interpretasi budaya masa lampau, maka perlu menambah wawasan terhadap 
metoda dan teknik pengumpulan data yang sesuai, dan menambah wawasan tentang lingkungan. Oleh karena itu mengenal dilajutkan dengan pelaksanaan metoda dan teknik pengumpulan data lingkungan merupakan tindakan yang patut diwujudkan

Tanpa ada pelaksanaan terhadap penerapan metoda pengumpulan data lingkungan tidak akan diketahui manfaat dan kendalanya Seringkali kendala tersebut muncul terutama belum maksimal dalam penerapan metoda, untuk itu diperlukan banyak kreasi dan inovasi baru guna memperoleh hasil yang maksimal

Hasil yang maksimal pada tahap pengumpulan data belum dapat memberi informasi apabila belum dilakukan analisis data. Analisis tersebut meliputi identifikasi dan determinasi temuan untuk memperoleh informasi jenisnya.

Beberapa teknik pengumpulan data vegetasi berikut beberapa di antaranya dapat digunakan dalam studi lingkungan kuna, dan dalam pemaparan berikut ditekankan hanya pada pengumpulan data vegetasi (mikrobotani) karena data ini dipandang sangat sulit dalam proses pengumpulan dan proses analisisnya.

\section{Metoda Pengumpulan Data Biotik}

Temuan sisa biotik tentu saja dapat memberi informasi untuk lingkungannya, terutama mengenai interpretasi tata lingkungan tempat hidup atau habitatnya dan tentang pola pemanfaatan yang dilakukan oleh manusia. Telaah lebih lanjut tentang data biotis dalam hubungannya dengan kehidupan manusia antara lain sebagai sumber bahan pangan (diet), bahan bangunan (tempat tinggal), bahan perabot, bahan penunjang kegiatan sehari-harinya, dan sebagai pelindung.

Setiap bagian tumbuhan, masing-masing mempunyai arti sangat penting sebagai data lingkungan, misalnya daun, buah, biji, batang (kayu dan arang), bunga (dalam hal ini yang tertinggal hanya serbuk sari atau pollen). Daun seringkali hanya ditemukan jejaknya, karena bagian tumbuhan ini tersusun dari jaringan lunak sehingga mudah rusak karena proses mekanik maupun proses dekomposisi Jejak daun yang ditinggalkan dapat memberikan keterangan tentang morfologinya. Menurut Dimbleby (1978) jejak daun sangat penting untuk interpretasi vegetasi, walaupun materi daun itu sendiri sudah hilang karena proses endapan materi batuan.

Analisis temuan flora dan fauna makroskopis tidak menjadi masalah karena temuan tersebut tampak bentuk dan atributnya. Namun sisa flora dan fauna yang mikroskopis, baik mikro-fauna maupun mikro-flora bahkan bagian tumbuhan yang ukurannya kecil memerlukan 
kecermatan tersendiri dalam pengumpulan data maupun analisisnya Metoda dan teknik pengumpulan data tumbuh-tumbuhan kini telah banyak mengalami perkembangan selaras dengan kemajuan ilmu pengetahuan dan teknologi. Beberapa teknik untuk mengenali sisa tumbuhan dapat digunakan beberapa metode antara lain metode pengapungan, analisis pollen, analisis diatom, dan analisis phytolith yang dapat diuraikan sebagai berikut

\subsection{Metoda pengapungan (float)}

Teknik Froth Flotation ini telah dikembangkan beberapa ahli ar. keologi lingkungan (Shackley, 1981; Evans, 1978). Pelaksanaan teknik ini pada prinsipnya mengapungkan benda-benda sisa biotik yang berasal dari dalam tanah, sampel tanah dari hasil ekskavasi dimasuk. kan dan diaduk dalam drum berisi air. Karena perbedaan berat jenis, maka tanah mengendap di dasar drum sedangkan benda-benda biotik seperti biji-bijian, daun, sisa ranting, arang, tulang, akan mengapung di permukaan air (Joukowsky, 1980). Benda biotik yang mengapung diambil dengan saringanlayakan. Cara lain air di permukaan drum dialirkan keluar melewati ayakan (flot sieves) sehingga sisa biotik tertampung pada ayakan. Air buangan dapat dimanfaatkan kembali (daur ulang) dengan memompa kedalam drum setelah pengendapan (lihat gambar 1).

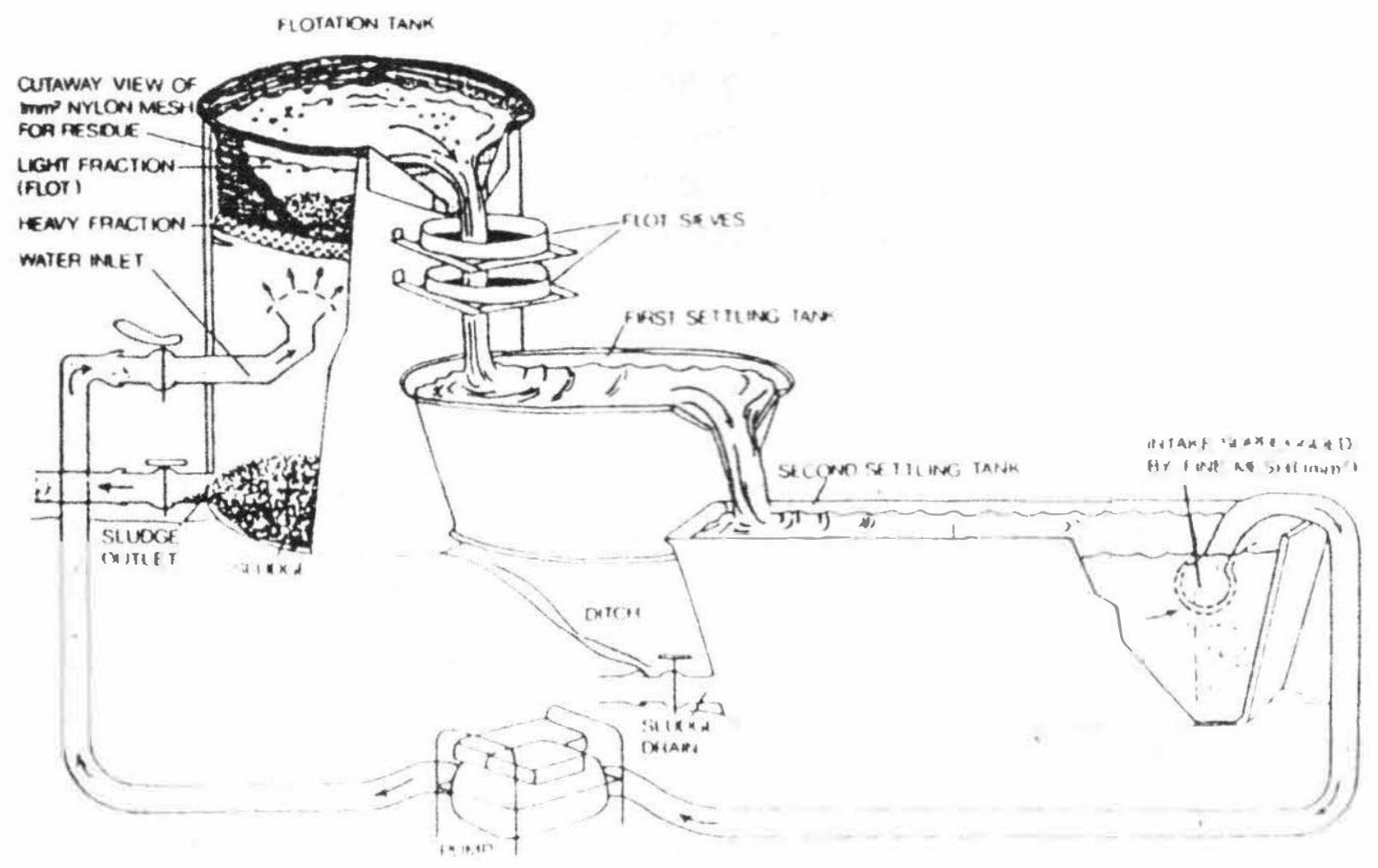

Gambar: 1. Water Flotation dengan sistem pembilasan dan mendaur ulang penggunaan air (Sumber: Renfrew \& Bahn, 1991) 
Temuan yang mengapung untuk dianalisis terdiri dari mikro -flora, mikro-fauna, serpih-serpih bagian tumbuhan (batang, ranting, biji, buah, arang, kulit, akar, daun, bunga), dan bagian dari sisa binatang (tulang, kuku, tanduk, bulu, cangkang, bahkan koprolit). Hasil yang didapatkan ada pengaruh dari cara dan kecermatan penerapan metoda serta kondisi situs yang diteliti

Seperti diketahui kondisi alam di permukaan bumi ini sangat heterogen, maka apa yang dapat dilakukan di suatu tempat belum tentu dapat dilakukan di tempat lain. Demikian pula dalam penerapan metoda diatas dalam pengumpulan data ekofak dan feature. Melalui beberapa pengalaman maka dalam pelaksanaannya menyesuaikan dengan kondisi alam (situs). Metoda froth flotation dalam pelaksanaannya mengalami beberapa kendala antara láin karena jenis tanah dan keadaan air.

Jenis tanah yang terlalu kompak seperti tanah yang bertekstur lempung atau bersifat lempungan. Jenis tanah ini tidak mudah terurai karena materi tanah dalam air tersebut tidak mudah melepaskan materi sisa biotik yang ada di dalamnya. Selain itu faktor kebasahan tanah juga ikut menentukan, apabila sampel tanah perlu di ayak terlebih dahulu sebelum dimasukkan alat froth flotstion, karena tanah kering atau lembab lebih mudah di ayak daripada tanah basah.

Sementara itu keberadaan air juga merupakan kendala. Keberadaan air di setiap situs tidak sama, sedangkan metoda ini memerlukan banyak air. Dengan demikian bagi situs yang jauh dari sumber air akan sangat mempengaruhi kerja penerapan metoda ini. Namun hal ini masih dapat di atasi dengan membawa sampel tanah ke tempat sumber air, sehingga dapat diproses dengan metoda yang ada

\subsection{Analisis Pollen}

Metoda ini suatu cara memperoleh informasi pada tumbuhan tingkat tinggi (phanerogamae) atau tumbuhan berbunga (Shackley, 1981). Metoda ini dikembangkan oleh ahli botani dari Swedia Lennart Van Post. Sisa sebagai data adalah serbuk sari tumbuhan (pollen) yang tertinggal di dalam tanah, hasilnya telah terbukti dapat memberikan sumbangan bagi arkeologi terutama penyediaan informasi vegetasi, iklim dan bahkan kronologi. Penerapan analisis pollen untuk kronologi yang paling cocok adalah untuk kala post glasial atau holosen (Renfrew \& Bahn, 1991).

Analisis pollen ini dalam kepentingan penyusunan studi lingkungan kuna untuk melengkapi data apabila pada metoda froth flotation diperoleh data yang kurang lengkap dan kurang mendukung

Berkala Arkeologi Th. XV - (2) . 


\subsection{Analisis Diatom}

Metoda lain dalam usaha untuk merekonstruksi lingkungan kuna adalah analisis diatom. Analisis ini menggunakan mikrofosil tumbuhan sebagi sampelnya (Renfrew \& Bahn, 1991). Diatom atau diatomae (Bacillariopphyceae) adalah tumbuhan tingkat rendah atau alga ber sel tunggal (uniseluler) yang hidup di perairan tawar, payau maupun laut (Evans, 1978). Alga kersik hidup melimpah di perairan laut maupun tawar mempunyai arti penting sebagai sumber makanan utama bagi ikan dan hewen laut maupun tawar lainnya.

Alga ini mempunyai dinding sel dari bahan silika, sehingga dinding sel ini bertahan setelah alga nya mati. Bila alga ini terurai atau dicerna oleh hewan, maka dinding selnya tidak busuk, tetapi tenggelam ke dasar air dalam jumlah yang besar akan membentuk suatu endapan yang biasa disebut "tanah diatom" yang sangat luas (Polunin, 1990). Analisis dan proses identifikasi alga dalam preparasi menggunakan teknik seperti dalam analisis polllen.

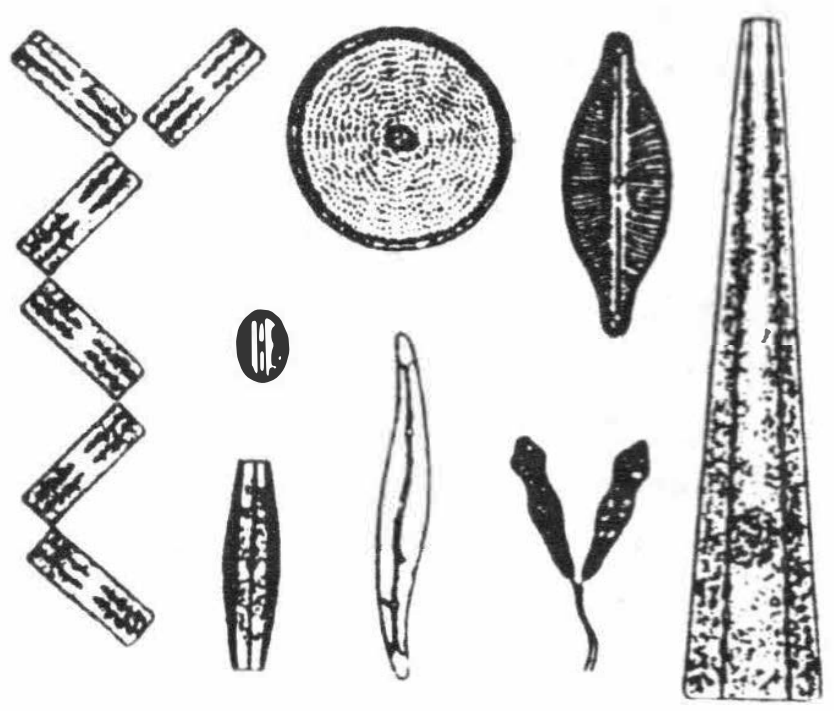

Gambar: 2. Berbagai bentuk sel diatom (Sumber: Polunin. 1990) 


\subsection{Analisis Phytoliths}

Phytoliths adalah bagian dari partikel silika yang berasal dari sel tumbuhan, bagian ini dapat bertahan setelah organisme itu mati dan terdekomposisi atau terbakar. Pada umumnya terdapat pada tungku (bekas perapian) atau lapisan abu, tetapi juga ditemukan pada keramik, plester, pada alat, danpada gigi herbivora ( Renfrew \& Bahn, 1991). Kombinasi analisis phytoliths dengan analisis pollen merupakan sarana yang kuat untuk merekonstruksi lingkungan kuna. Pelaksanaan analisis phytoliths ini pada prinsipnya seperti metoda analisis pollen, karena bagian tumbuhan ini biasanya berukuran sangat kecil yaitu antara 20 - 50 mikron (Shiffer, 1983).

Di samping sisa-sisa mikro-flora, temuan sisa fauna sama pentingnya sebagai data lingkungan. Pada umumnya sisa fauna yang diperoleh berupa tulang, tanduk, gigi sisa binatang dari kelompok vertebrata, sedangkan kelompok avertebrata sering diperoleh berupa sisa kerang (moluska). Metoda pengumpulan data fauna seperti halnya pengumpulan data flora yaitu melalui ekskavasi dan survai permukaan tanah.

Data yang diperoleh berupa sisa hayati seperti tulang, kayu, biji, daun, serbuk sari dan lainnya dilakukan dengan analisis secara mikroskopis maupun makroskopis untuk meliputi identifikasi dan determinasi, untuk memperoleh jenis temuan sebagai daya dukung temuan agar mencapai tujuan penelitian.

\section{Penutup}

Studi lingkungan khususnya lingkungan kuna, merupakan salah satu hal penting dan perlu untuk dilaksanakan, karena keluarannya dapat dipakai sebagai bahan acuan dan memberikan kontribusi dalam studi ilmu lingkungan saat ini, khususnya studi tata ruang. Bidang studi lingkungan yang baru dimulai kira-kira empat puluh tahun yang lalu belum banyak memiliki acuan, apalagi acuan lingkungan masa lampau sangat minim. Untuk memprediksi lingkungan masa yang akan datang di samping mempelajari lingkungan sekarang juga mempelajari lingkungan masa lampau, karena dari prosesnya akan dapat kita ketahui kecenderungan atau arah perkembangannya.

Berangkat dari masa lampau agar dapat menjabarkan lingkungan kunanya, diperlukan data pokok, yaitu sisa yang terdapat di sekitar objek. Sementara itu, teknik pengumpulan data perlu peningkatan inovasi secara terus menerus yang diimbangi dengan penyempurnaan teknik dan metoda yang telah ada tentu saja kendala-kendala yang timbul perlu diperhatikan 
Lebih penting lagi dalam analisis temuan, hal yang paling menentukan untuk memperoleh informasi dari hasil analisis data. Walaupun dengan cara yang sempurna dalam perolehan data namun tidak akan mendapatkan informasi apa-pun bila temuan tersebut tidak dianalisis atau mengalami kegagalan

\section{Kepustakaan}

Dimbleby, Geoffrey. 1978. Plant and Archaeology. Paladin Granada Publishing, London, Toronto, Sidney, New York.

Evans, John G. 1978, Environmental Archaeology. Paul Elek, London Joukowsky, M. 1980. A Complete Manual of Field Archaeology, Tools and Tecniques of Field Work for Archaeologists. Prentice-Hall, Inc., Englewood Cliffs, New Jersey.

Martopo, Sugeng. 1994. Peranan Arkeologi Dalam Studi Lingkungan. Artefak - No.14/Agustus 1994. Fakultas Sastra UGM. Yogyakarta.

Polunin, Nicholas, 1990. Geografl Tumbuhan (Terjemahan oleh: Gembong Tjitrosupomo, Editor: Wibisono Soerodikoesoemo). Gadjah Mada University Press. Yogyakarta.

Renfrew, Colin \& Bahn, Paul.1991. Archaeology - Theories, Methods and Practice. Thames and Hudson Ltd, USA.

Sciffer, MB.(Ed.). 1983. Arhaeological Method and Theory. Academic Press, New York, London.

Shackley,M. 1981. Environmental Archaeology George Allen \& Unwin London, Boston, Sydney.

Watson. Patty Jo, Le Blanc, dan CL Redman, 1971. Explanation in Archaeology, An Explicitly Scentific Approach. Columbia University Press, New York. 


$$
4783 / B A 4 / H / 99
$$

